\title{
Cancer of the nose and paranasal sinuses in the metal industry: a case-control study
}

\author{
Pietro Comba, Pietro Gino Barbieri, Giuseppe Battista, Stefano Belli, Francesco Ponterio, \\ Diego Zanetti, Olav Axelson
}

\begin{abstract}
The association between nasal cancer and work in the metal industry was investigated in a case-control study located in the province of Brescia, north eastern Italy. Thirty five cases of malignant epithelial neoplasms of the nasal cavity and paranasal sinuses who were resident in the province of Brescia and diagnosed or treated by the ear, nose, and throat department and the radiotherapy unit (Centro Alte Energie) of the Brescia Hospital in the years 1980-9 were included in the study. Controls (102) were patients affected by benign and malignant neoplasms of the head and neck who were resident in the Brescia Province and matched the cases by age and sex. All the subjects were interviewed by telephone. Metal workers showed an increased risk of nasal cancer (odds ratio (OR) $3 \cdot 1$; $90 \%$ confidence interval ( $90 \%$ CI) $0 \cdot 48-20)$; a higher risk was associated with work in foundries (OR 5.9; 90 CI 0.77-46). Work in wood, leather, and textile industries was also associated with increased risk of nasal cancer.
\end{abstract}

The first reported case of occupationally induced cancer of the paranasal sinuses occurred in a chromate pigment manufacturer who developed the neoplasm several years after suffering from a chromate induced perforation of the septum. ${ }^{1}$ Early reports also appeared about nasal cancer in the nickel

Istituto Superiore di Sanità, Viale Regina Elena, 299 00161 Rome, Italy

P Comba, S Belli

Local Health Authority, Iseo (Brescia)

P G Barbieri

Unit of Workers' Preventive Medicine, University of Siena

G Battista

Ear, Nose and Throat Department, Hospital of Brescia

F Ponterio, D Zanetti

Institute of Occupational Medicine, University of Linköping

O Axelson refinery workers of the Mond factory in Wales. ${ }^{23}$ Subsequent epidemiological investigations on nasal cancer in the metal industry have confirmed an occupational cancer risk from chromium ${ }^{4-6}$ and nickel compounds. ${ }^{7-11}$ Besides chromium and nickel workers, foundry workers, ${ }^{12}{ }^{13}$ welders, ${ }^{14}$ and toolmakers ${ }^{15}$ appeared to have increased risk of nasal cancer.

In a case-control study carried out at the National Cancer Institute in Milan, an odds ratio (OR) of 4.5 (95\% confidence interval (95\% CI) 1.4-14.2) was associated with metal work; the job titles at high risk were those of smelter, smith, and mechanic. ${ }^{16}$

Investigations into the risk of nasal cancer in the metal industry are of interest for two main reasons: firstly, the association of nasal cancer with specific job titles in the metal industry might help to identify the aetiologically relevant exposures. Secondly the detection of an increased risk of nasal cancer, which is a rare disease, can be predictive of the presence of a carcinogenic hazard in general and for the respiratory tract in particular.

The purpose of the present study was to investigate the occurrence of nasal cancer, especially in relation to exposures in the metal industry. The study was located in the province of Brescia in northern Italy, east of Milan, where the metal industry has a longstanding tradition. According to the 1981 national census, $31 \%$ of the active male population worked in this industrial sector. Average annual mortalities for nasal cancer in the province of Brescia in the years $1983-7$ were 5.32 and 0.77 per million person-years in men and women respectively. In the same quinquennium the corresponding rates in Italy were 2.33 and 1.36 cases per million person-years.

\section{Materials and methods}

The study concerned a population of about a million inhabitants, and included cases of malignant epithelial neoplasms of the nasal cavity and paranasal sinuses diagnosed and treated by the ear, nose, and throat (ENT) department and the "Centro Alte Energie" (radiotherapy unit) of the Brescia Hospital from 1980 to the end of 1989. Cases diagnosed in 
Brescia but resident in other provinces were excluded. Controls were selected from the files of the ear, nose, and throat (ENT) department and the radiotherapy unit and included patients affected by benign and malignant neoplastic diseases of head and neck, excluding epidermoid carcinomas of the tongue, oral cavity, oro- and hypopharynx, and larynx. These tumours are known to be associated with intake of alcohol, and a different distribution of alcohol consumption among cases and controls could have resulted in an unbalanced distribution of social class, ultimately leading to spurious associations between the disease of interest and various occupations. Four controls resident in the Brescia province were matched to each case taking into account age (five year classes) and sex. When it was not possible to find four controls complying with the admissibility criteria, fewer were recruited. Altogether, 35 cases and 102 controls were enrolled in the study. One case and four controls refused to be interviewed; the four controls were substituted.

Cases and controls, or the next of kin if the subject had died, were contacted over the telephone by a trailed interviewer who filled in a questionnaire without knowing whether the subject was a case or a control. The information collected included a detailed occupational history plus a number of specific items, especially concerning work in the metal industry but also work in leather and wood industries, which was regarded as a potential confounder.

The material was analysed by means of the biomedical data program (BMDP) statistical package. A stratified analysis was performed using the Mantel and Haenszel procedure ${ }^{17}$ and $90 \%$ confidence intervals $(90 \% \mathrm{CIs})$ were estimated according to the approximate method of Miettinen.$^{18}$ Logistic regression analyses were performed according to the BMPD program.

\section{Results}

Table 1 shows the age and sex distribution of cases and controls. Among men, 82.6\% of cases and $65.7 \%$ of controls were smokers resulting in an odds ratio (OR) of 2.5 (90\% CI 0.93-6.6). Among women, the corresponding proportions of smokers were $27 \%$ and $13 \%$ respectively, with OR $2 \cdot 6(90 \%$ CI $0 \cdot 65-10 \cdot 3)$.

Table 2 shows the ORs and the corresponding $90 \%$ CIs associated with different occupations for men. Although it was not intended to study the wood and leather industries, a 10-fold increase in risk was associated with this kind of work and a still higher risk was associated with work in the textile and garment industry. Three out of four cases who had worked in this area had presumably been exposed to cotton dust, two of them being sock manufacturers, and one being a cotton garment worker. No corresponding risk was seen, however, for women in this industry. Metal workers showed a threefold increase in risk, which did not reach statistical significance; if foundry workers alone were considered, the $O R$ was $5.9(90 \%$ CI $0.77-46)$. To further investigate the association between work in the metal industry and nasal cancer, the potential confounding role of cigarette smoking was assessed by means of logistic regression analysis. The ORs adjusted for smoking were $2 \cdot 8(90 \% \mathrm{CI} 0 \cdot 4-19)$ for metal workers and 10 (90\% CI $0.9-110)$ for foundry workers. If the analysis was restricted to patients with adenocarcinoma, two cases appeared to be foundry workers, whereas no case was unexposed. One of the two adenocarcinoma cases had been a leather worker as well as a foundry worker. Some extra risk was associated with farming, breeding, and other occupations entailing exposure to dusts and fumes (table 2).

Among women a non-significant increase in risk was associated with farming (table 3 ).

\section{Discussion}

The present study was especially aimed at studying the risk of nasal cancer for metal workers and a threefold increase in risk was found for this occupation. Foundry workers and smelters had an OR of 5.9 , but the few cases found resulted in a wide $90 \%$ CI that included unity.

Nevertheless, these findings confirm previous observations by us and by other authors.

A study on the incidence of nasal cancer in England and Wales detected a significant risk associated with work in furnaces, foundries, forges, and rolling mills, the standardised incidence ratio being $250 .{ }^{12}$ In a case control study performed in Denmark, Olsen ${ }^{13}$ showed significantly increased standardised proportionate incidence ratios (SPIRs) associated with work in the basic metal industry (SPIR = 351), manufacture of metal packaging (SPIR $=571)$ and bodywork $($ SPIR $=600)$. A hospital based programme of surveillance of nasal cancer in Italy detected 17 cases of nasal cancer among metal workers ${ }^{19}$; a subsequent case-control study carried out at the National Cancer

Table 1 Age and sex distribution of cases and controls

\begin{tabular}{lccc}
\hline & Cases & Controls & Total \\
\hline Men: & & & \\
$<60$ & 10 & 31 & 41 \\
$61-70$ & 3 & 14 & 17 \\
$\geqslant 70$ & 10 & 25 & 35 \\
Total & 23 & 70 & 93 \\
Women: & & & \\
$<60$ & 3 & 8 & 11 \\
$61-70$ & 1 & 7 & 8 \\
$\geqslant 70$ & 7 & 17 & 24 \\
Total & 11 & 32 & 43 \\
\hline
\end{tabular}

Age range 28-88. 
Table 2 Odds ratios for men associated with various occupations

\begin{tabular}{|c|c|c|c|}
\hline & No of cases & OR (crude) & OR $(\log )(90 \% C I)$ \\
\hline $\begin{array}{l}\text { Woodworkers* } \\
\text { Leather workers } \\
\text { Metal workers } \dagger \\
\text { foundry workers } \\
\text { Textile and garment workers } \dagger \\
\text { Miners and construction workers } \dagger \\
\text { Farmer } \dagger \\
\text { Breeders } \dagger \\
\text { Other occupations entailing exposure to dusts and fumes } \dagger \\
\text { All occupational exposures } \\
\text { Reference }\end{array}$ & $\begin{array}{r}3 \\
1 \\
9 \\
5 \\
4 \\
5 \\
4 \\
2 \\
4 \\
22 \\
1\end{array}$ & $\begin{array}{r}13 \cdot 5 \\
9.0 \\
2.9 \\
6 \cdot 4 \\
18 \\
3 \cdot 8 \\
1.6 \\
3.0 \\
1 \cdot 8 \\
3.3 \\
1 \cdot 0\end{array}$ & $\begin{array}{l}11(0 \cdot 85-139) \\
3 \cdot 1(0 \cdot 48-20) \\
5 \cdot 9(0 \cdot 77-46) \\
17(1 \cdot 9-162) \\
1 \cdot 2(0 \cdot 11-13) \\
1.9(0 \cdot 25-14) \\
2 \cdot 0(0 \cdot 09-43) \\
1 \cdot 5(0 \cdot 18-12) \\
(0 \cdot 59-18) \\
1 \cdot 0\end{array}$ \\
\hline
\end{tabular}

^Adjusted for age.

†Adjusted for age and exposure to wood and leather dusts.

Institute in Milan showed an OR of 4.5 (95\% CI 1.4 $14 \cdot 2) .^{16}$

Although the epidemiological investigations carried out so far have not clearly indicated the nature of the causative agent for nasal cancer in the metal industry, relatively large particles coated with polycyclic aromatic hydrocarbons might play an aetiological part. This hypothesis is consistent with the finding of an increased risk of nasal cancer among gas workers. ${ }^{2021}$ Foundry workers can be exposed not only to aromatic polycyclic hydrocarbons, but also to metal dusts and to mineral oil mists; furthermore, urethane and other plastic products are found in the casting forms.

The high risk of nasal cancer in wood workers and textile workers is consistent with earlier findings. For wood workers it is generally agreed that the high incidence of nasal cancer is causally related to the inhalation of wood dust. ${ }^{22-24}$

Also the finding for textile workers appears to be consistent with data from various countries that suggest an aetiological role for textile dusts. Exposure to cotton dust has been shown to be associated with nasal cancer ${ }^{25}$ This was subsequently confirmed by Brinton et al, ${ }^{2627}$ who found an increased risk of nasal cancer among textile workers employed in dusty occupations. The occurrence of nasal cancer in the textile industry has been further described in Sweden, ${ }^{28}$ Hong Kong, ${ }^{29}$ Denmark, ${ }^{13}$ and Italy. ${ }^{16}$

For the province of Brescia major improvements in

Table 3 Odds ratios for women associated with various occupations

\begin{tabular}{|c|c|c|}
\hline & $\begin{array}{l}\text { No of } \\
\text { cases }\end{array}$ & $\begin{array}{l}\text { OR }(90 \% C I) \\
\text { (crude) }\end{array}$ \\
\hline $\begin{array}{l}\text { Textile and garment workers } \\
\text { Farmers } \\
\text { Other occupations entailing }\end{array}$ & $\begin{array}{l}3 \\
4\end{array}$ & $\begin{array}{l}0.82(0.20-3 \cdot 3) \\
2 \cdot 0(0 \cdot 51-7 \cdot 9)\end{array}$ \\
\hline $\begin{array}{l}\text { exposure to dusts and fumes } \\
\text { Reference }\end{array}$ & $\begin{array}{l}1 \\
5\end{array}$ & $\begin{array}{l}1 \cdot 5(0 \cdot 16-14) \\
1 \cdot 0\end{array}$ \\
\hline
\end{tabular}

the work environment in the textile industry occurred in the 1980s with regard to the air concentration of dusts and mineral oils.

Our present study suffered from low statistical power because of the low incidence of the disease. An indication of a sixfold increase in risk, however, was still obtained for foundry workers. Any major bias is unlikely to affect this investigation; the selection of cases and controls did not imply recruitment of subjects conditionally on their exposure patterns, the collection of information was performed blindly with respect to case and control state, and the effect of established risk factors for nasal cancer (inhalation of wood dust and leather dust) was taken into account by means of logistic regression. Cigarette smoking, a suspected aetiological agent of nasal cancer ${ }^{263031}$ was also taken into account by means of modelling.

The excess risk of nasal cancer among foundry workers and textile workers appears to reflect a causal phenomenon and it seems appropriate to recommend the adoption of remedial action, essentially by abating ambient dust concentrations.

We thank Ms Maria Teresa Pezzin for her invaluable contribution to the collection of information in the present study.

Requests for reprints to: Dr Pietro Comba, Istituto Superiore di Sanità, Viale Regina Elena 299 00161, Rome, Italy.

1 Newman D. A case of adeno-carcinoma of the left inferior turbinated body, and perforation of the nasal septum, in the person of a worker in chrome pigments. Glasgow Medical Journal 1890;33:469-70.

2 Bridge JC. Annual report of the chief inspector of factories for the year 1932. London: His Majesty's Stationery Office, 1933:103-4.

3 Amor AJ. Growths of respiratory tract. VIII Internationaler Kongress für Unfallmedizin und Berufskankheiten 1938;2: 941-62.

4 Hueper WC. Occupational and environmental cancers of the respiratory system. Rec Results Cancer Res 1966;3:59-85.

5 Enterline PE. Respiratory cancer among chromate workers. $J$ Occup Med 1974;16:523-6.

6 Alderson MR, Rattan NS, Bildstrup L. Health of workmen in 
the chromate producing industry in Britain. $\mathrm{Br} J$ Ind Med 1981;38:117-24.

7 Doll R. Cancer of the lung and nose in nickel workers. $\mathrm{Br} J$ Ind Med 1958;15:217-23.

8 Sunderman FW. Epidemiology of respiratory cancer among nickel workers. Diseases of the Chest 1968;54:527-34.

9 Doll R, Morgan LG, Speizer FE. Cancers of the lung and nasal sinuses in nickel workers. Br J Cancer 1970;24:623-32.

10 Pedersen E, Hogetveit A, Andersen A. Cancer of respiratory organs among workers at a nickel refinery in Norway. Int $J$ Cancer 1973;12:32-41.

11 Kaldor J, Peto J, Easton D, Doll R, Hermon C, Morgan L. Models for respiratory cancer in nickel refinery workers. J Natl Cancer Inst 1986;77:841-8.

12 Acheson ED, Cowdell RH, Rang EH. Nasal cancer in England and Wales: an occupational survey. $\mathrm{Br} J$ Ind Med 1981;38: 218-24.

13 Olsen JH. Occupational risks of sinonasal cancer in Denmark. $\mathrm{Br}$ J Ind Med 1988;45:329-35.

14 Hernberg $S$, Westerholm P, Schultz-Larsen $K$, Degerth $R$, Kuosma E, Englund A, et al. Nasal and sinonasal cancer. Connection with occupational exposures in Denmark, Finland and Sweden. Scand JWork Environ Health 1983:315-26.

15 Roush GC, Meigs JW, Kelly J, Flannery JT, Burdo H. Sinonasal cancer and occupation: a case-control study. $A m ~ J$ Epidemiol 1980;111:183-93.

16 Bimbi G, Battista G, Belli S, Berrino F, Comba P. Nasal cancer and occupational exposures: a case-referent study. In: Hogstedt C, Reuterwall C, eds. Progress in occupational epidemiology. Amsterdam: Elsevier, 1988:99-102.

17 Mantel N, Haenszel W. Statistical aspects of the analysis of data from retrospective studies of disease. J Natl Cancer Inst 1959;23:719-48.

18 Miettinen $O$. Estimability and estimation in case-referent studies. Am J Epidemiol 1976;103:226-35.

19 Vetrugno T, Comba P. Indagine policentrica sui tumori del naso e dei seni paranasali e le attività lavorative in Italia 1983-1985. Acta Otorhinolaryngologica Italica 1987;7:485-94.

20 Bruusgaard A. Opptreden av visse kreftformer blant gassverkarbeidere. Tidsskr Nor Laegeforen 1959;79:755-6.

21 Gustavson P, Reuterwall C. Mortality and incidence of cancer among Swedish gas workers. Br J Ind Med 1990;47:169-74.

22 Macbeth R. Malignant disease of the paranasal sinuses. $J$ Laryngol 1965;79:592-612.

23 Acheson ED, Cowdell RH, Hadfield E, Macbeth RG. Nasal cancer in woodworkers in the furniture industry. $B M J$ 1968;2:587-96.

24 International Agency for Research on Cancer. Monographs on the evaluation of carcinogenic risks to humans, suppl 7. Overall evaluation of carcinogenicity: an updating. Lyon: IARC, 1987.

25 Acheson ED, Cowdell RH, Rang E. Adenocarcinoma of the nasal cavity and sinuses in England and Wales. Br J Ind Med 1972;29:21-30.

26 Brinton LA, Blot WJ, Becker JA, et al. A case-control study of cancers of the nasal cavity and paranasal sinuses. Am J Epidemiol 1984;119:896-906.

27 Brinton LA, Blot WJ, Fraumeni JF. Nasal cancer in the textile and clothing industries. Br J Ind Med 1985;42:469-74.

28 Malker HSR, McLaughlin DJK, Blott WJ, et al. Nasal cancer and occupation in Sweden, 1961-1979. Am J Ind Med 1986;9: 477-85.

$29 \mathrm{Ng}$ TP. A case-referent study of cancer of the nasal cavity and sinuses in Hong Kong. Int J Epidemiol 1986;15:171-5.

30 Elwood JM. Wood exposure and smoking: association with cancer of the nasal cavity and paranasal sinuses in British Columbia. Can Med Assoc J 1981;124:1573-7.

31 Hayes RB, Kardaun JWPF, de Bruyn A. Tobacco use and sinonasal cancer: a case-control study. $B r J$ Cancer 1987 $56: 843-6$.

Accepted 15 July 1991 